\title{
Direct Laser Cladding of Cobalt on Ti-6Al-4V with a Compositionally Graded Interface
}

\author{
Jyotsna Dutta Majumdar \\ Department of Metallurgical and Materials Engineering, Indian Institute of Technology, Kharagpur 721302, India \\ Correspondence should be addressed to Jyotsna Dutta Majumdar, jyotsna@metal.iitkgp.ernet.in
}

Received 1 March 2011; Accepted 21 May 2011

Academic Editor: Smurov Igor

Copyright ( $) 2011$ Jyotsna Dutta Majumdar. This is an open access article distributed under the Creative Commons Attribution License, which permits unrestricted use, distribution, and reproduction in any medium, provided the original work is properly cited.

\begin{abstract}
Direct laser cladding of cobalt on Ti-6Al-4V with and without a graded interface has been attempted using a continuous wave $\mathrm{CO}_{2}$ laser. Graded interface is developed by depositing a thin copper layer on Ti-6Al-4V substrate prior to multiple laser cladding of cobalt on it. Presence of copper interlayer was found to suppress the formation of brittle intermetallics of Ti and Co. The effect of process parameters on the microstructures, compositions, and phases of the interface was studied in details. Finally, the mechanical and electrochemical properties of the interface processed under optimum process parameters are reported.
\end{abstract}

\section{Introduction}

The conventionally replaced hip consists of three parts; a ball which rotates in a hollow socket, and it is fixed into the femur (thigh bone) by a stem [1]. Co-Cr-Mo is the most appropriate alloy for the ball because of its very high elastic modulus and its wear and corrosion resistance [1]. On the other hand, Ti-6Al-4V alloy is the most acceptable stem material. The ball and stem may be held together with a taper. Though the use of multimaterials seems economical to prepare component for hip replacement, loosening of metals from the interface because of fretting and corrosion attack is a severe problem. It has been observed that maximum performance and service life of the bio implants may be achieved when the component is made of a single material. Direct laser cladding is a technique where fabrication of solid components is achieved by laser-assisted melting of the materials in the form of particles/wire, deposition of molten layer on a substrate in a layer by layer fashion and thereby, building of the full component using computer-aided design (CAD) [2]. Notable advantages of the technique over conventional fabrication techniques include faster processing speed, no requirement of tooling, ability to fabricate complex shapes, and retention of metastable microstructure/composition [3]. Arcella and Froes [4] reported on the laser forming of tita- nium. Srivastava et al. [5] reported on the direct laser fabrication of $\mathrm{Ti} 48 \mathrm{Al} 2 \mathrm{Mn} 2 \mathrm{Nb}$ alloy and established the role of process parameters on the microstructure. Effect of process parameters on the quality of the DLD layers have been studied by Syed \& Li [6] and Majumdar et al. [7]. In the present study, attempts have been made to fabricate a Co layer on the surface of Ti-6Al-4V substrate by direct laser cladding technique with an objective to develop the ball on a stem made of Ti-6Al-4V for hip and femoral prostheses. Attempt has been made to suppress the formation of intermetallics between $\mathrm{Co}$ and $\mathrm{Ti}$ by application of a thin $\mathrm{Cu}$ layer on $\mathrm{Ti}$ substrate by electrodeposition technique. A copper interlayer has been used to suppress the interdiffusion of titanium and cobalt and hence, suppressing the formation of a brittle intermetallics [8]. Following fabrication, a detailed investigation of the microstructure, composition, and phase of the fabricated layer has been undertaken. Finally, the wear and corrosion properties of the fabricated part have been studied in details.

\section{Experimental}

In the present study, commercially pure Ti-6Al-4V (of dimensions $15 \mathrm{~mm} \times 15 \mathrm{~mm} \times 5 \mathrm{~mm}$ ) was chosen as substrate. A thin layer ( $30 \mu \mathrm{m}$ thickness) of copper was deposited 


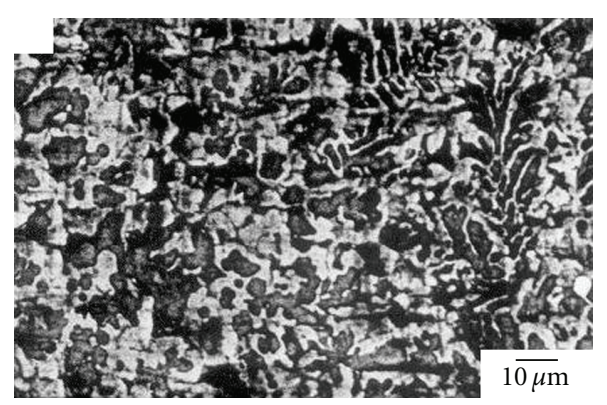

(a)

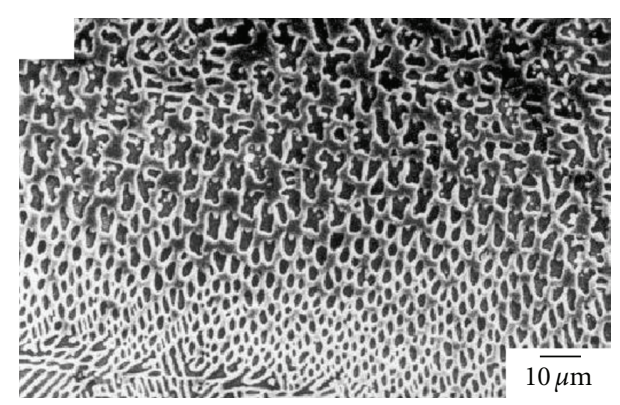

(b)

FIGURE 1: Scanning electron micrographs of the alloyed zone formed at the interface of direct laser clad Co on Ti, (a) without Cu and (b) with $\mathrm{Cu}$ coating at a thickness of $30 \mu \mathrm{m}$.

TABle 1: Summary of Young's Modulus of as-received Ti-6Al-4V and direct laser clad Co on Ti-6Al-4V without any interlayer and with a $30 \mu \mathrm{m}$ copper interlayer.

\begin{tabular}{lc}
\hline Sample history & $\begin{array}{c}\text { Young's } \\
\text { modulus } \\
(\mathrm{GPa})\end{array}$ \\
\hline $\begin{array}{l}\text { Ti-6Al-4V } \\
\text { Interface of cobalt clad on titanium without copper } \\
\text { interlayer }\end{array}$ & $1140-150$ \\
$\begin{array}{l}\text { Interface of cobalt clad on titanium with a } 30 \mu \mathrm{m} \\
\text { copper interlayer }\end{array}$ & $140-240$ \\
\hline
\end{tabular}

on diamond polished Ti-6Al-4V substrate by electrodeposition. Co layer was developed on the electrodeposited (Ti$6 \mathrm{Al}-4 \mathrm{~V}$ substrate using multiple laser cladding technique by pre-deposition of elemental Co powder (of size ranging from $20 \mu \mathrm{m}$ and to a thickness of $500 \mu \mathrm{m}$ ) by spraying with the desired elemental powder dispersed in alcohol with organic binder and subsequently, laser melting it with a continuous wave $\mathrm{CO}_{2}$ laser with an applied power of $1-2 \mathrm{~kW}$ and scan speed of 500-1250 mm/min using Ar as shrouding environment. Following the development of clad layer, the microstructures of the clad layer and interface (both on topsurface and cross-sectional plane) were studied by scanning electron microscope (SEM). Compositional distribution was monitored by energy-dispersed X-ray spectroscopy (EDS). Phases present and its distribution were determined by $\mathrm{X}$-ray diffractometer (XRD) using Co-K $\alpha$ radiation. Wear resistance property of the formed layer was studied using a ball-on-plate friction and wear monitor unit (model no.: TR-208-M1) comprising a diamond pyramid indenter rotating on the specimen with a predetermined speed of $15 \mathrm{rpm}$ ) and normal load of $1 \mathrm{~kg}$. Kinetics of wear as a function of time under different load was monitored by converting the vertical displacement of the indenter into cumulative wear loss using Winducom 2003 software. The Young's modulus distribution at the interface was carefully analyzed using nanoindentation technique (by application of a triangular pyramid (Berkovich) diamond indenter). TestWorks 4 software for nanoindentation system is used to calculate hardness and Young's modulus from loaddisplacement graph using the Oliver and Pharr method [9].
Finally, the corrosion behavior of the cross-section of equal segments of clad-alloyed-substrate combinations were carried out in Hank's solution ( $(\mathrm{g} / \mathrm{l}): 0.185 \mathrm{CaCl}_{2}, 0.4$ $\mathrm{KCl}, 0.06 \mathrm{KH}_{2} \mathrm{PO}_{4}, 0.1 \mathrm{MgCl}_{2}, 6 \mathrm{H}_{2} \mathrm{O}, 0.1 \mathrm{MgSO}_{4} \cdot 7 \mathrm{H}_{2} \mathrm{O}, 8$ $\mathrm{NaCl}, 0.35 \mathrm{NaHCO}_{3}, 0.48 \mathrm{Na}_{2} \mathrm{HPO}_{4}$, and 1.00 D-glucose) by potentiodynamic cyclic polarization test at a scan rate of $2 \mathrm{mV} / \mathrm{s}$ from -500 to $+5000 \mathrm{mV}$ (SCE) using standard calomel as reference electrode and platinum as counter electrode [10].

\section{Results and Discussions}

Microstructures play a crucial role in determining the properties and behavior of the components in practical service. In the present study, a detailed investigation of the effect of laser parameters and coating thickness on the morphology of the microstructure was undertaken to optimize the process parameters. Figures 1(a) and 1(b) show the scanning electron micrographs of the alloyed zone formed in direct laser clad $\mathrm{Co}$ on $\mathrm{Ti}$, (a) without $\mathrm{Cu}$ coating and (b) with $\mathrm{Cu}$ coating at a coating thickness of $30 \mu \mathrm{m}$. From Figure 1 it is relevant that the microstructures of the alloyed zone mainly consist of intermetallic phases distributed uniformly all throughout the matrix. The morphology of the microstructures is a mixture of dendrites and cellular. A comparison between Figure 1(a) with Figure 1(b) shows that presence of $\mathrm{Cu}$ at the interface, significantly refines the microstructures (As evident from interdendritic arm spacing). The refinement of microstructure due to the application of copper coating is possibly because of a rapid cooling rate associated with a large thermal conductivity of coated copper at the interface. In this regard, it is relevant to mention that the area fraction and nature of precipitates were found to vary with the thickness of $\mathrm{Cu}$ coating. However, it was observed that application of a very thick $\mathrm{Cu}$ interlayer leads to formation of fine micro cracks in the alloyed zone due to presence of a very large area fraction of intermetallics. A careful analysis of the microstructures and residual stress distribution at the interface shows an optimum coating thickness to be of $30 \mu \mathrm{m}$.

A detailed elemental distribution with depth showed that distribution of $\mathrm{Co}$ in the alloyed region is maximum $(20 \mathrm{wt} \%)$ at the clad layer-alloyed zone interface and 
TABLE 2: Corrosion behavior of the dissimilar interface in a $3.56 \mathrm{wt} . \% \mathrm{NaCl}$ solution.

\begin{tabular}{lcc}
\hline Sample history & $E_{\mathrm{pp} 1} \mathrm{mV}(\mathrm{SCE})$ & Corrosion rate $(\mathrm{mm} / \mathrm{year})$ \\
\hline Ti-6Al-4V & 1300 & $1.07 \times 10^{-3}$ \\
Interface of cobalt clad on titanium without copper interlayer & 437 & $2.43 \times 10^{-3}$ \\
Interface of cobalt clad on titanium with a 30 mm copper interlayer & 700 & $1.26 \times 10^{-3}$ \\
\hline
\end{tabular}

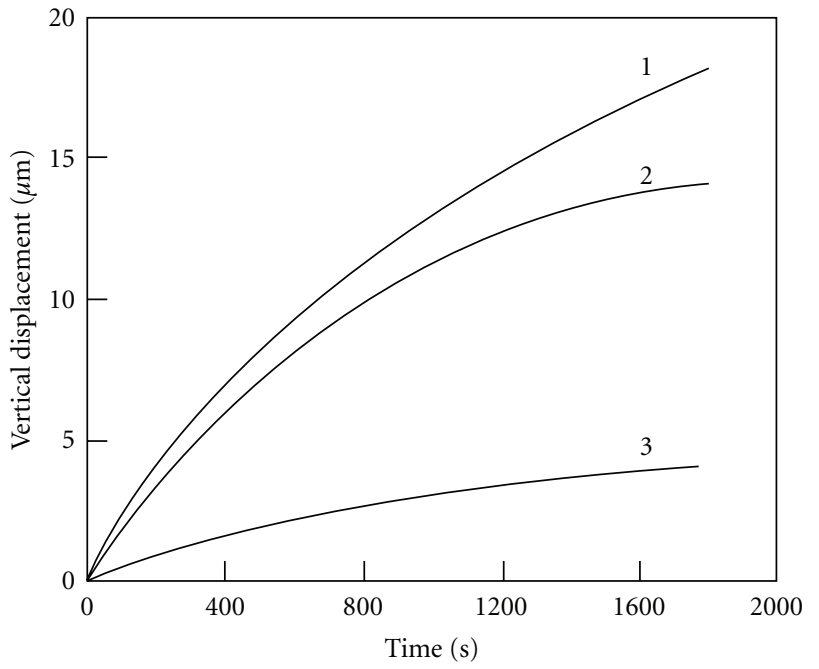

Figure 2: Wear profiles of (1) Ti substrate and Co clad Ti lased with laser power density, $\mathrm{P}$ of $0.212 \mathrm{~kW} / \mathrm{mm}^{2}$ and scan speed, $\mathrm{v}$ of $14.3 \mathrm{~mm} / \mathrm{s}$ for (2) without $\mathrm{Cu}$ interlayer and with $\mathrm{Cu}$ interlayer with thickness of (3) $30 \mu \mathrm{m}$ at $1 \mathrm{~kg}$ load.

decreases gradually with depth reaching a minimum level to $5 \mathrm{wt} \%$ at the alloyed zone-substrate interface. Addition of $\mathrm{Cu}$ interlayer leads to its melting, intermixing with $\mathrm{Ti}$ and $\mathrm{Co}$ and changing the composition/microstructures of alloyed zone significantly. A detailed elemental analysis showed that a $10 \mathrm{wt} \%$ of $\mathrm{Cu}$ was uniformly distributed all throughout the alloyed zone. X-ray diffraction profiles of the interface reveal the presence of intermetallics of $\mathrm{Co}$ and $\mathrm{Ti}$ $\left(\mathrm{Ti}_{2} \mathrm{Co}\right)$. This intermetallic is very brittle and is detrimental to the toughness property of the interface. On the contrary, application of $\mathrm{Cu}$ interlayer on $\mathrm{Ti}$ prior to laser cladding with Co causes formation of a number of intermetallics between $\mathrm{Cu}$ and $\mathrm{Ti}$ (mainly $\mathrm{CuTi}_{3}, \mathrm{Cu}_{3} \mathrm{Ti}$ and suppresses the formation of $\mathrm{Ti}_{2} \mathrm{Co}$ completely, though there was a presence of $\mathrm{TiCo}_{2}$ phase at the interface).

Figure 2 shows the wear profiles of (1) Ti substrate and at the interface of Co clad Ti lased with laser power density of $0.212 \mathrm{~kW} / \mathrm{mm}^{2}$ and scan speed of $14.3 \mathrm{~mm} / \mathrm{s}$ for (2) without $\mathrm{Cu}$ interlayer and with $\mathrm{Cu}$ interlayer with thickness of (3) $30 \mu \mathrm{m}$, respectively. Wear test was carried out with standard Diamond indenter with $1 \mathrm{~kg}$ load. A relatively lower wear resistance of the interface where, Co was clad on Ti-6Al-4V without any interlayer is attributed to the presence of $\mathrm{Ti}_{2} \mathrm{Co}$ which is brittle and hence, leads to spalling effect during abrasive wear against diamond indenter. From plot 3 the effect of $\mathrm{Cu}$ interlayer on wear resistance is clearly noted. The excellent wear resistance of $\mathrm{CuTi}_{3}, \mathrm{Cu}_{3} \mathrm{Ti}$ protects the formed layer against the dry sliding wear. In addition, the rapidly solidified homogeneous fine microstructure imparts the coatings good combination of strength and toughness, which also contributes to the excellent resistance of the coating to spallation and delamination during dry sliding wear process. Table 1 summarizes the average Young's modulus of as-received and the interface of the direct laser clad cobalt on titanium without and interlayer and with $30 \mu \mathrm{m}$ thick copper interlayer. From Table 1 it may be noted that Young's modulus of the interface without the interlayer is increased to $130-150 \mathrm{GPa}$ as compared to as-received Ti-6Al-4V (114 GPa). On the other hand, application of $\mathrm{Cu}$ interlayer increases Young's modulus further to a level of 140-240 GPa. Improved Young's modulus due to the application of copper interlayer is attributed to the presence of several Ti-Cu intermetallics (like $\mathrm{CuTi}_{3}, \mathrm{Cu}_{3} \mathrm{Ti}$, etc.).

The corrosion behaviour of the interface was studied using potentiodynamic polarization test. Table 2 represents the results of the potentiodynamic polarization test conducted in Hank's solution for Ti substrate and the interface of laser clad $\mathrm{Co}$ on $\mathrm{Ti}$ without copper deposition and with copper deposition lased with laser power density of $0.212 \mathrm{~kW} / \mathrm{mm}^{2}$ and scan speed of $14.3 \mathrm{~mm} / \mathrm{s}$. The polarization test was conducted in forward cycle to determine the critical potential for pit formation $\left(E_{\mathrm{pp} 1}\right)$ values. From Table 1 it is clear that $E_{\mathrm{pp} 1}$ value for laser clad Co on $\mathrm{Ti}$ with $\mathrm{Cu}$ interlayer $(700 \mathrm{mV})$ shows improvement compared to laser clad $\mathrm{Co}$ on $\mathrm{Ti}$ without $\mathrm{Cu}$ interface $(437 \mathrm{mV})$. However, the formation of intermetallics like $\mathrm{CuTi}_{3}, \mathrm{Cu}_{3} \mathrm{Ti}$ results in low $E_{\mathrm{pp} 1}$ value compared to as-received Ti substrate $(1300 \mathrm{mV})$. The improvement in the pitting corrosion property due to the addition of copper interlayer is attributed to formation of a lower area fraction of precipitates in the later. On the other hand, corrosion rate of interface of cobalt clad titanium without copper interlayer is slightly deteriorated as compared to as-received Ti- $6 \mathrm{Al}-4 \mathrm{~V}$. On the other hand, at the interface of cobalt clad on titanium with a $30 \mu \mathrm{m}$ copper interlayer the corrosion rate is almost similar to Ti-6Al-4V substrate.

\section{Conclusions}

Direct laser cladding of cobalt on Ti-6Al-4V with and without a copper interlayer was attempted using a continuous wave $\mathrm{CO}_{2}$ laser. Graded interface is developed by depositing a thin copper layer on Ti-6Al-4V substrate prior to multiple laser cladding of cobalt on it. Presence of copper interlayer was found to increase both the wear resistance and Young's modulus significantly due to the presence of intermetallics between $\mathrm{Ti}$ and $\mathrm{Cu}\left(\mathrm{CuTi}_{3}, \mathrm{Cu}_{3} \mathrm{Ti}\right.$, etc.) which are less brittle as compared to the intermetallics between $\mathrm{Ti}$ and Co $\left(\mathrm{Ti}_{2} \mathrm{Co}\right)$. Corrosion resistance of the interface in Hank's 
solution was marginally deteriorated due to the presence of multiphase in the structure. The degree of deterioration is less where a copper interlayer was applied prior to the direct laser cladding of cobalt on it. The pitting potential was significantly reduced at the interface of direct laser clad cobalt on titanium without any copper interlayer, though marginally reduced in the case where $\mathrm{Cu}$ interlayer was applied, which is attributed to a lower area fraction of intermetallic in the structure.

\section{Acknowledgments}

Partial financial support from Department of Science and Technology (DST, New Delhi), Council of Scientific and Industrial Research (CSIR, New Delhi), Board of Research in Nuclear Science (BRNS, Bombay), and Naval Research Board (NRB, New Delhi) are gratefully acknowledged. Technical discussions with Professor I. Manna and Professor A. K. Nath are also gratefully acknowledged.

\section{References}

[1] Bhat S. V., Ed., Biomaterials, Narosa Publishing House, N. Delhi, India, 2002.

[2] W. M. Steen, Laser Material Processing, Springer, New York, NY, USA, 1991.

[3] J. Dutta Majumdar and I. Manna, "Laser processing of materials," Sadhana, vol. 28, no. 3-4, pp. 495-562, 2003.

[4] F. G. Arcella and F. H. Froes, "Producing titanium aerospace components from powder using laser forming," Journal of Metals, vol. 52, no. 5, pp. 28-30, 2000.

[5] D. Srivastava, I. T. H. Chang, and M. H. Loretto, "The effect of process parameters and heat treatment on the microstructure of direct laser fabricated TiAl alloy samples," Intermetallics, vol. 9, no. 12, pp. 1003-1013, 2001.

[6] W. U. H. Syed and L. Li, "Effects of wire feeding direction and location in multiple layer diode laser direct metal deposition," Applied Surface Science, vol. 248, no. 1-4, pp. 518-524, 2005.

[7] J. D. Majumdar, A. Pinkerton, Z. Liu, I. Manna, and L. Li, "Microstructure characterisation and process optimization of laser assisted rapid fabrication of 316L stainless steel," Applied Surface Science, vol. 247, no. 1-4, pp. 320-327, 2005.

[8] T. B. Massalski, Binary Alloy Phase Diagrams, ASM International, Materials Park, Ohio, USA, 1990.

[9] W. C. Oliver and G. M. Pharr, "Improved technique for determining hardness and elastic modulus using load and displacement sensing indentation experiments," Journal of Materials Research, vol. 7, no. 6, pp. 1564-1580, 1992.

[10] M. G. Fontana, Corrosion Engineering, McGraw-Hill, New York, NY, USA, 1987. 

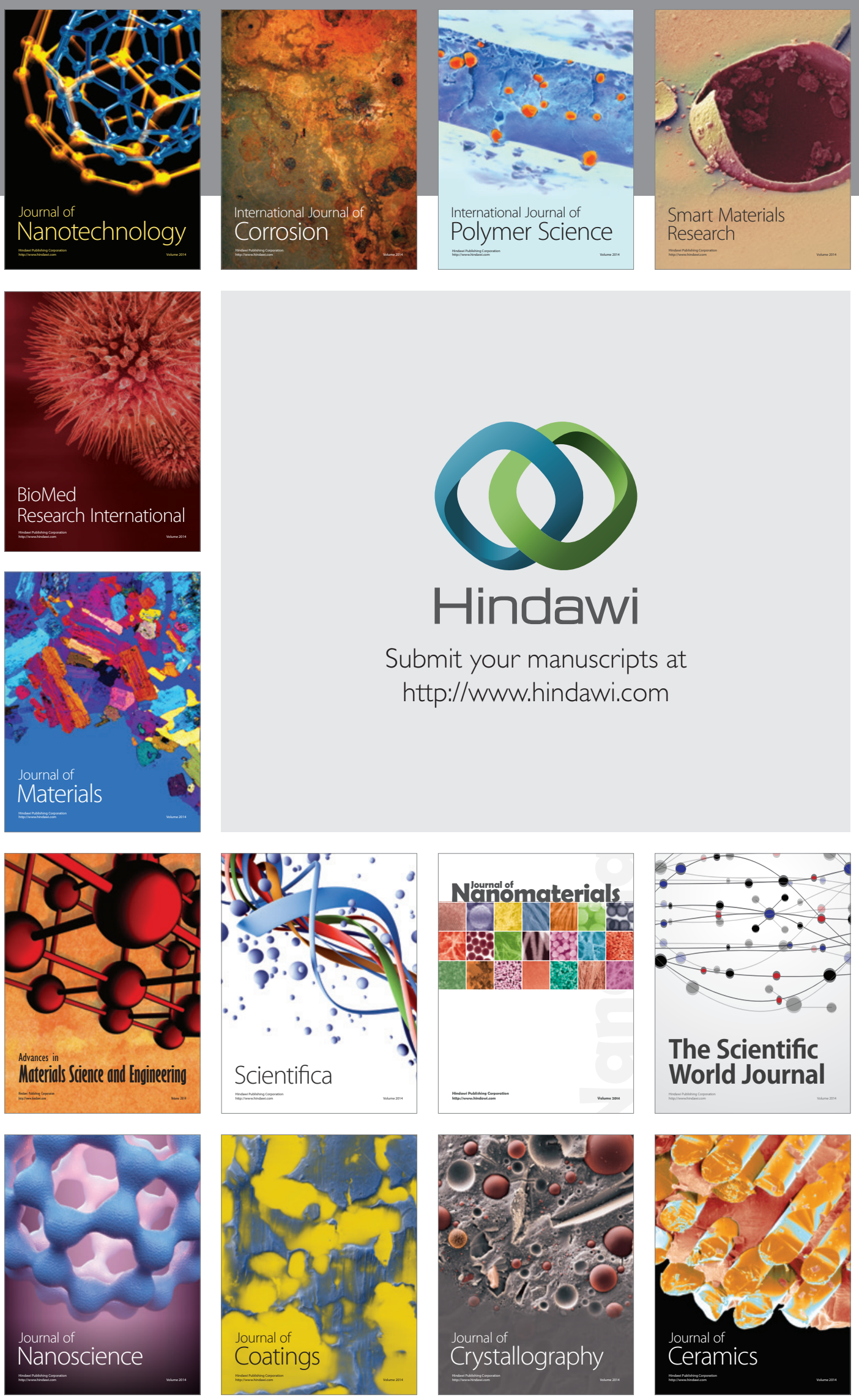

The Scientific World Journal

Submit your manuscripts at

http://www.hindawi.com

\section{World Journal}

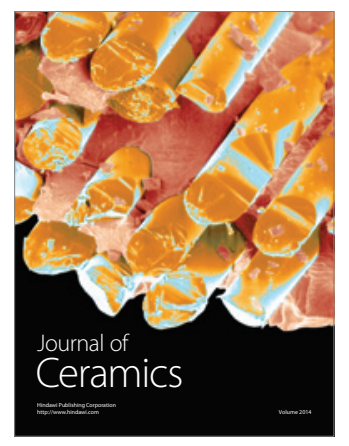

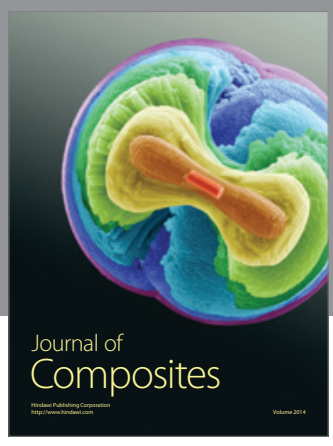
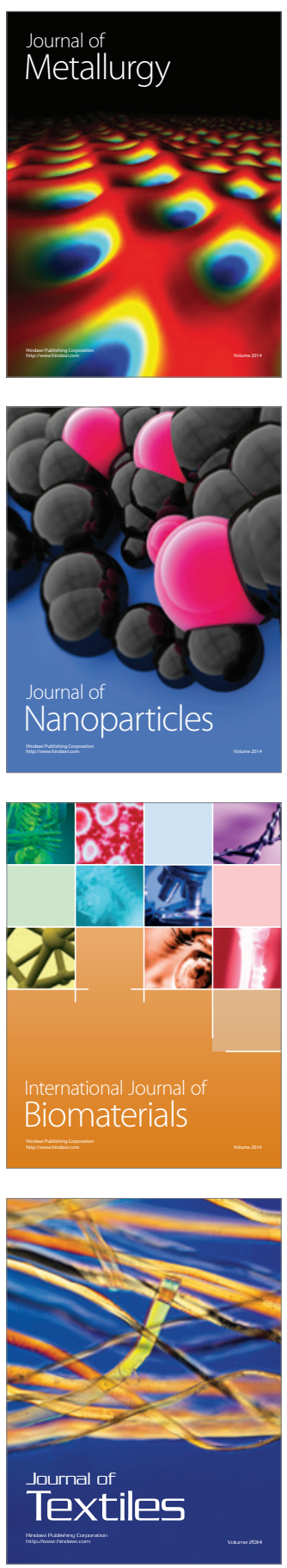